\title{
Preliminary results of tests on nitrogen cushion for combating fire hazard in longwalls rich in methane
}

\author{
Dawid Szurgacz $^{1 *}$, Leszek Sobik ${ }^{2}$, Jarosław Brodny ${ }^{3}$, and Maxim Grigashkin ${ }^{4}$ \\ ${ }^{1}$ Center of Hydraulics DOH Ltd, ul. Konstytucji 147, 41-906 Bytom, Poland \\ ${ }^{2}$ Polska Grupa Górnicza S.A., KWK ROW ruch Chwałowice, ul. Przewozowa 4, 44-206 Rybnik, \\ Poland \\ ${ }^{3}$ Silesian University of Technology, Faculty of Organization and Management, Roosevelta 26, \\ 41-800 Zabrze, Poland \\ ${ }^{4}$ NUST "MISiS", Department of Energy and Energy Efficiency of the Mining Industry, 119049 \\ Moscow, 4 Leninskiy prospect, Russia
}

\begin{abstract}
Ventilation hazard is the most dangerous phenomena occurring in the hard coal extraction process. This particularly applies to endogenous fire hazard. In order to reduce it, it is necessary to improve the effectiveness of preventive measures. Hence this paper presents new solutions that substantially improve fire prevention effectiveness. The main idea is to develop and create an additional nitrogen cushion in the zone behind the powered roof support operating in a longwall face. The solution is based on installations for inerting of goafs and sections of the powered roof support. The nitrogen cushion restricts the access of air and oxygen to the area of goafs and limits the possibility of fire. Practical application of the developed solution allowed for effective reduction of fire hazard in conditions of a very high tendency of coal to self-ignite at short incubation period. This, in turn, enables safe exploitation and decommissioning of the longwall. Undoubtedly, the solution presented and the results obtained constitute a new approach to preventive actions in mines. It is the result of the work of theoretical and practical researchers. The solution is a combination of the potential of these two environments. The developed solution should find wide range of applications in the areas where endogenous fire and methane hazards occur.
\end{abstract}

\section{Introduction}

The development of world economy has been based on electricity which is mainly produced from coal. Only continuous improvement and advancement of the extraction process ensures that it is economically justified and safe. In recent years there has been a dynamic development of new technologies aimed at boosting the efficiency and safety of the coal production process [8]. Currently used mining systems are based on powered longwall complexes. One of the basic machines of this complex is a powered roof support.

*Corresponding author: dawidszurgacz@doh.com.pl 
It is crucial in terms of continuity of the production process and thus a wide range of studies and research are focused on the improvement of the support [1-9]. The search for innovative solutions and need to adjust to worsening conditions of the mining process result from numerous types of natural hazards that are linked to the extraction process including ventilation hazards, i.e. methane and fire hazards which are particularly dangerous. Methane hazards are mainly associated with flammable and explosive properties of methane [12-20]. Fire hazards, however, are linked to endogenous and exogenous fires. All incidents related to these hazards are extremely dangerous to the crew and the machines in operation.

In recent years, the number of cases of endogenous and exogenous fires in underground hard coal mines in Poland have significantly increased.

Detail data on the number of cases recorded between 2014 and 2019 are presented in Fig. 1.

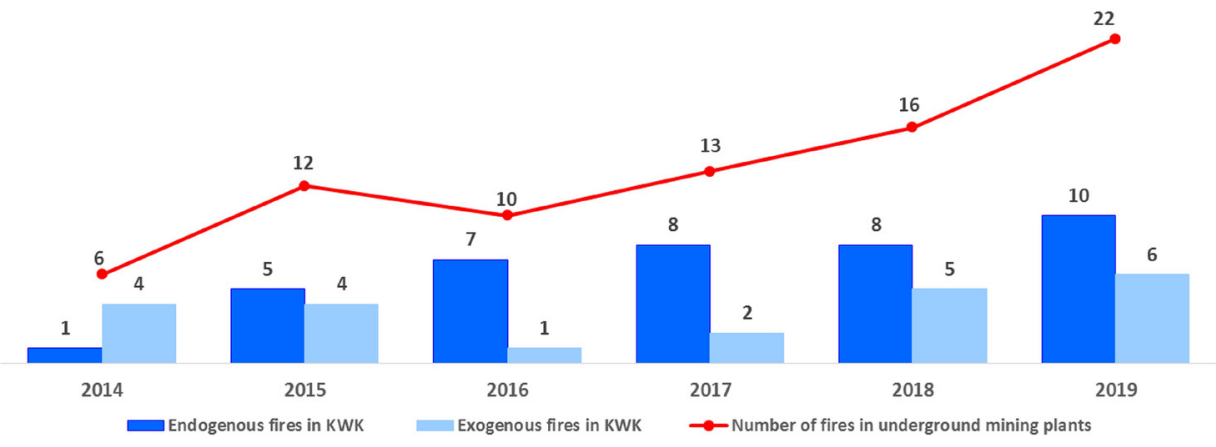

Fig. 1. Cases of endogenous and exogenous fires in underground mines recorded between 2014 and 2019 [21].

The chart clearly indicates that the level of fire hazards in Polish mines is high. It is therefore necessary to take action to reduce the possibility of dangerous events associated with these hazards. The paper focuses on the development of an effective method to reduce endogenous fire hazard [12-20]. Mining plants use almost all general means available to eliminate the fires. The mines should carry on permanent fire prevention measures, significantly extended, that is based mainly on feeding the ash-water mixture and inert gases, such as nitrogen or carbon dioxide, to the goafs $[10,11]$.

The use of ash in volatile form as ash and water mixtures for fire prevention by sealing and insulating goafs and filling the post-mining voids are common techniques applied in Polish mines. These are effective but currently insufficient measures. Consequently, it is necessary to support the prevention with gas inerting (nitrogen or carbon dioxide inerting). Fire prevention methods based on inerting with inert gases (nitrogen or carbon dioxide) should be continuously improved due to their effectiveness. Many years of experience in the use of inert gases was the foundation of the new solution-development of the nitrogen cushion using the powered roof support. The application of this solution should significantly increase the effectiveness of the inerting in combating the hazard of endogenous fires.

An endogenous fire may be caused by the coal left in the goaf during the exploitation of the longwall using a longitudinal system with U-ventilation system. One of the main causes of the increase of probability of the fire is slowed down or periodically halted mining process in the longwall. Consequently, the probability of fire in these goafs increase. This, in turn, can pose a serious threat to the maintenance of the continuity of operations in the area where the fire has occurred. 
The research team decided to develop a new solution that will allow to create the nitrogen cushion with the sections of the powered roof support in the longwall where the occurrence of endogenous fire in the coal deposit is highly probable. The article presents the essence of this solution and the result of its practical application.

\section{Characteristics of the developed solution}

Figure 2 shows a diagram explaining the basic assumptions of the proposed solution. Its foundation is fire prevention based on nitrogen inerting - an inert gas is feed to the goafs and insulation with chemical foams. This approach makes it possible to create the nitrogen cushion in goafs.

In the presented case, the mining process was conducted in diversified mining and geological conditions. The roof comprised locally sanded shale (mudstone) and the floor comprised shale. The longwall was classified as water hazard level I and methane hazard category IV. The tests of coal deposited in the seam where the mining process was conducted showed a very high susceptibility to self-combustion (group V of selfcombustion). This coal is characterised by a spontaneous combustion index $\mathrm{Sza}=127$ ${ }^{\circ} \mathrm{C} / \mathrm{min}$ and activation energy $\mathrm{A}=47 \mathrm{~kJ} / \mathrm{mol}$. The calculated incubation period of endogenous fire was only 34 days. This is a noticeably short period of time, which, with favourable ventilation conditions, can quickly lead to an endogenous fire.

The proposed solution assumes the installation of a pipe, 3 metre long and $50 \mathrm{~mm}$ wide, in the sections of the powered roof support in the area with the highest concentrations of carbon monoxide (Fig. 2). Pipes were built in on average every two or four sections of the powered roof support. They were connected by means of inerting hoses with distributors equipped with control valves. The whole structure was connected to the nitrogen supply main running along the entire length of the longwall.

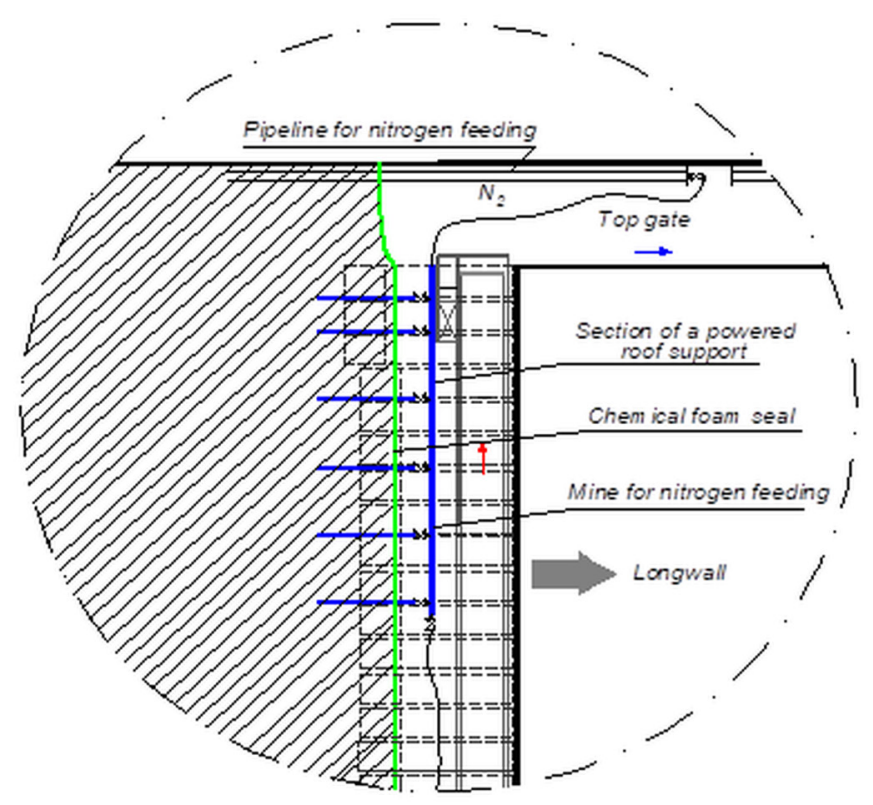

Fig. 2. Fire prevention solution based on nitrogen inerting in the goafs in the longwall and insulation with chemical foams allowing the creation of a nitrogen cushion. 
An inert gas - nitrogen - was fed through the built-in pipes in order to create the nitrogen cushion in the goaf where the highest concentrations of carbon monoxide were found. At the same time, inert gas was successively fed through the pipelines left in the goafs of the top and bottom gates.

\section{Research results}

The supply of nitrogen through the pipes left in the seams behind the powered roof support sections made it possible to create the nitrogen cushion. Thanks to it, oxygen was removed from the goaf, so the atmosphere became oxygen deficient and fresh air was not allowed to penetrate between sections of the powered roof support to the goaf space, where there was the highest probability of coal heating.

The results of the measurement and regulation of aerodynamic potentials around the goafs contributed to the implementation of the developed solution. The regulation allowed to reduce the drop in the potentials affecting the goafs, which made it possible to maintain an atmosphere in the goafs that hinders the oxidation of carbon-inert atmosphere.

The application of the developed solution allowed to deliver nitrogen (in gaseous form) directly to the caving zone of the longwall, which contributed to the reduction of oxygen content and slowed the process of self-heating. This also resulted in a favourable change of the potential system in the aerodynamic region of the longwall, thanks to which a significant part of oxygen was pushed out of the caving zone and replaced with nitrogen inhibiting the existing coal heating.

Inerting resulted in substantial decrease of fire hazard in the longwall during decommissioning. Nevertheless, in the first phase of use of the above mentioned system, the results of precise chromatographic analyses taken from the probe place in the top gate confirmed a sudden increase in carbon monoxide and other $\mathrm{C} 2-\mathrm{C} 4$ unsaturated hydrocarbons such as ethylene, propylene or acetylene.

Figures 3, 4 and 5 show the results of carbon monoxide and C2-C4 unsaturated hydrocarbon content formation recorded by the probe located in the caving area of the top gate. These results are related to the case of application of the developed solution based on feeding inert gas - nitrogen — to goafs and insulating the goafs with chemical foams. These measures contribute to the creation of the nitrogen cushion. It is evident that the solution has significantly improved the ventilation parameters.

The solution used in a longwall during decommissioning show that the developed fire preventive measures based on nitrogen inerting and insulation with chemical foams and the nitrogen cushion are highly effective in terms of endogenous fires prevention.

The whole range of preventive measures carried out in this longwall indicates that this new approach to fire prevention can have very tangible and positive effects. The implementation of new, scientifically based methods into mines is most advisable and should become a standard, especially in the field of improving safety at work. 


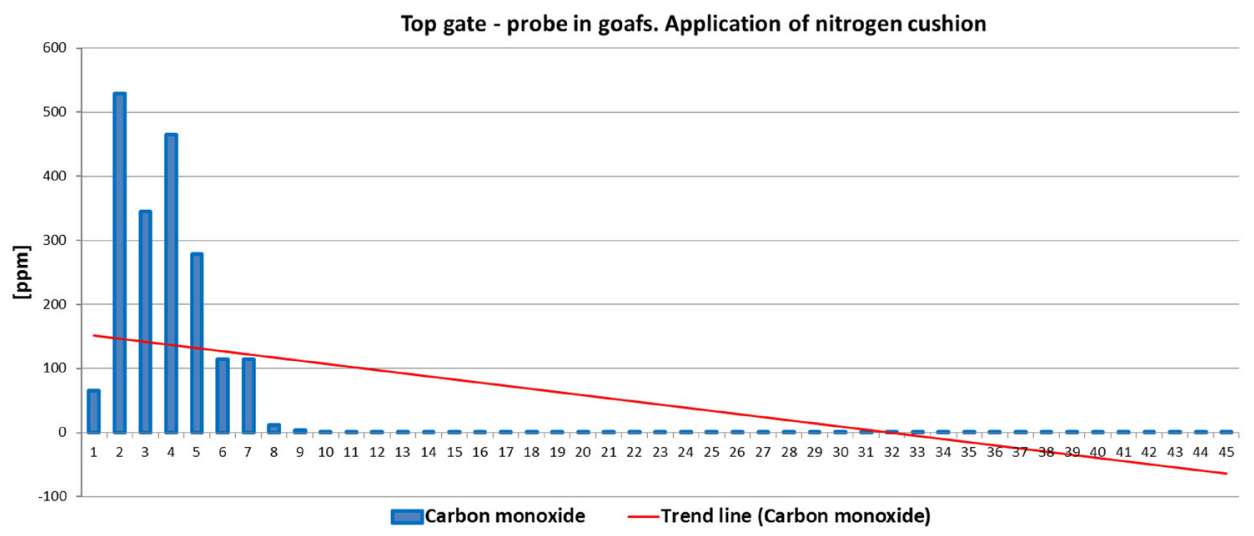

Fig. 3. Changes in the concentration of carbon monoxide in gas samples taken from the probe located $\mathrm{n}$ the caving zone of the top gate.

The presented solution has numerous applications, both in mines which have not yet applied the presented methods of comprehensive measures, as well as for those which have extensive experience in fire prevention. Comprehensive fire prevention methods combined with the presented solution should significantly improve the conditions of the extraction process.

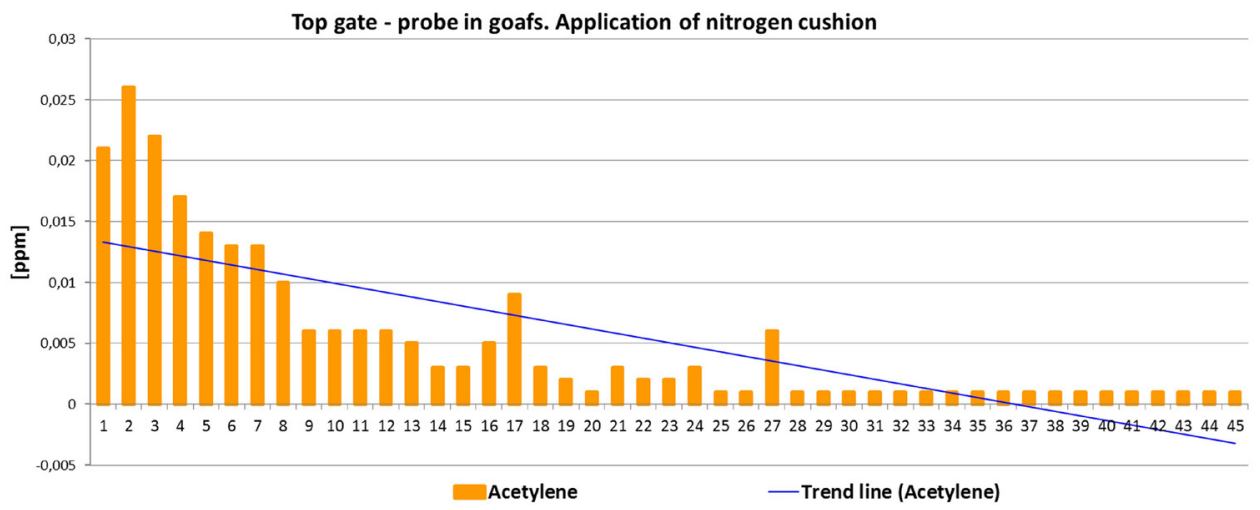

Fig. 4. Changes in the concentration of ethylene and propylene in gas samples taken from the probe located in the caving zone of the top gate. 


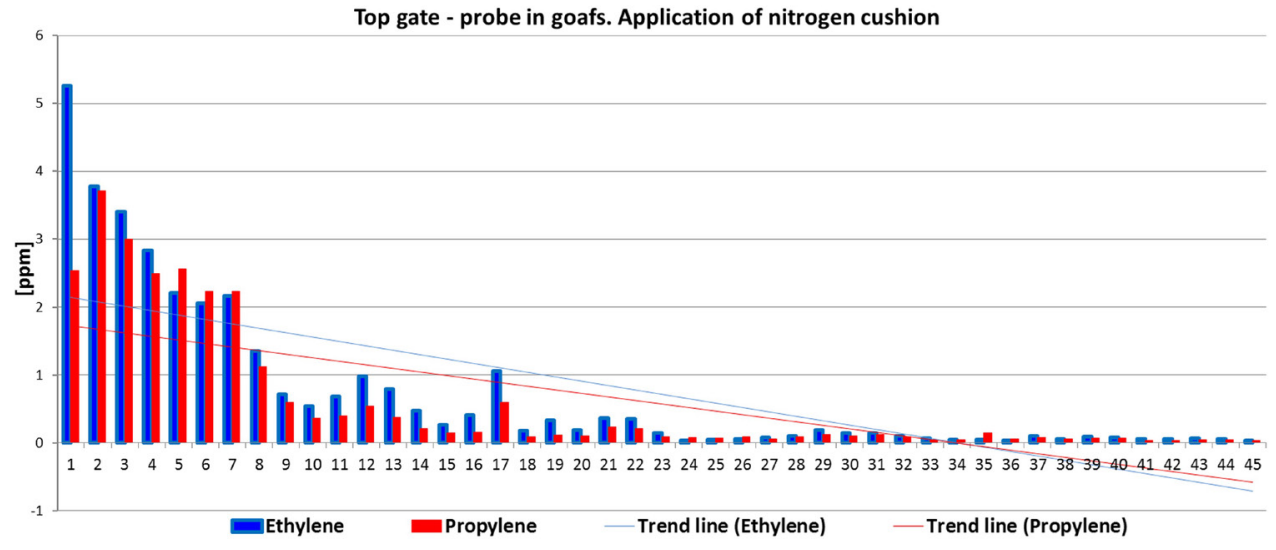

Fig. 5. Changes in the concentration of acetylene in gas samples taken from the probe located in the caving zone of the top gate.

\section{Conclusion}

Preventive measures are the primary tools in combating endogenous fires hazard. Such hazard constitutes a huge threat and consequently the these tools must be continuously improved. The use of the nitrogen cushion and the powered roof support contributed to the reduction of the fire hazard in the goafs, which had remained at a high level. The tests carried out proved that after the application of this solution, the concentrations of carbon monoxide in the current flowing out of the longwall were always lower than the permissible content (26 ppm) and ranged from 6 to $18 \mathrm{ppm}$. The amount of carbon monoxide in the goafs was 12 litres per minute. It must therefore be assumed that there has been a significant decrease in the rate of fire incidents.

The developed solution is the key element of the mining process based on seams rich in methane. Feeding gaseous nitrogen directly to the caving zone of the longwall insulates the goafs and therefore provides regular ventilation of the excavations. Limited access of oxygen to the goafs secures them from possible spontaneous heating of coal.

Preventive measures extended with nitrogen inerting and insulation with chemical foams boost safety of works carried out near the extraction process. The solution is the result of long-standing research and extensive experience in reducing the hazard of endogenous fires. The authors hope that it will contribute to the improvement of work safety in mines and will find wide range of applications.

\section{References}

1. M. Blaschuk, A. Dronov, A. Koperchuk, R. Chernukhin, V. Litvienko, E3S Web of Conferences, 15, 03003 (2017)

2. G. D. Buyalich, K. G. Buyalich, V. V. Voyevodin, IOP Conference Series: Materials Science and Engineering, 91, 012087 (2015)

3. G. D. Buyalich, K. G. Buyalich, V. V. Voyevodin, IOP Conf. Series: Materials Science and Engineering. - IOP Publishing, 127, 012034 (2016)

4. G. Buyalich, K. Buyalich, M. Byakov, E3S Web Conf., 21, 22671242 (2017)

5. G. Buyalich, M. Byakov, K. Buyalich, E3S Web Conf., 41, (2018)

6. G. Buyalich, M. Byakov, K. Buyalich, E. Shtenin, E3S Web Conf., 105, 03025 (2019) 
7. V. I. Klishin, T.M. Tarasik, Jour. of Min. Sci., 37, 77-84 (2001)

8. S. Zhironkin, S. Demchenko, G. Kayachev, E. Taran, O. Zhironkina, E3S Web Conf., 105, 03008 (2019)

9. I. Yermakova, V. Fedusov. E3S Web Conf., 105, 01049 (2019)

10. D. Szurgacz, L. Sobik, J. Brodny, Multidiscip. Aspe. of Produ. Engine., Vol. 2:1,183190, (2019). DOI:doi.org/10.2478/mape-2019-0018

11. D. Szurgacz, L. Sobik, J. Brodny, E3S Web Conf., 105, 01013; (2019)

12. J. Brodny, M. Tutak, Arch. Control Sci., 29:1, 25-39 (2019)

13. M. Tutak, M. Sustainability, 12:1, 16 (2020). DOI:doi.org/10.3390/su12010016

14. M. Tutak, J. Brodny, Appl. Sci., 9:24, 5315 (2019). DOI:doi.org/10.3390/app9245315

15. M. Tutak, J. Brodny, Energies, 12:20, 3840 (2019)

16. M. Tutak, J. Brodny, Int. J. Environ. Res. Public Health, 16:8, 1406 (2019)

17. J. Brodny, M. Tutak, J. Appl. Fluid Mech., 11:3, 545-553 (2018)

18. J. Brodny, M. Tutak, A. John., Mechanika, 24:5, 695-702 (2018)

19. M. Tutak, J. Brodny, IOP Conference Series: Earth and Environmental Science, 95:4, 042026 (2017)

20. M. Tutak, J. Brodny, IOP Conference Series: Earth and Environmental Science, 95:4, 042025 (2017)

21. WUG, Ocena stanu bezpieczeństwa pracy, ratownictwa górniczego oraz bezpieczeństwa powrzechnego w związu z działalnościa górniczo-geologiczna w 2018 roku (WUG, Krakow, 2018) 